\title{
Argamassa autonivelante com adição de resíduos de mármores e granitos: propriedades físicas e mecânicas
}

\author{
Self-levelling mortar with addition of marble and granite \\ waste: physical and mechanical properties
}

\begin{abstract}
Gabriela Azambuja Mendes
Carmeane Effting

Adilson Schackow

\section{Resumo}

$\mathbf{F}$

oram desenvolvidas misturas de argamassas autonivelantes para contrapiso com resíduos do corte de mármores e granitos (adição de $40 \%$ e 50\% RCMG em relação à massa de cimento), e sem o resíduo, variando-se a quantidade de aditivo modificador de viscosidade e superplastificante, relação água/cimento e cimento/areia. Sequencialmente foram ensaiadas dosagens com fíler calcário em substituição ao RCMG, com adição de fibras de polipropileno, e foi estudado um produto comercializado. Propriedades nos estados fresco (espalhamento/flow, healing time, retenção de fluxo após 20min e 30min e tempo de pega) e endurecido (massa específica, absorção de água, índice de vazios, resistência à compressão e tração na flexão) foram ensaiadas conforme a ASTM 1708. A mistura otimizada com 50\% RCMG, fator água/cimento de 0,55, proporção cimento/areia de 1:1,5 (em massa utilizando o cimento CPV-ARI) obteve resistência à compressão de 38,89 $\pm 2,10 \mathrm{MPa}$ aos 28 dias, apresentando o melhor desempenho entre as argamassas testadas. A adição de material fino nas dosagens de argamassas autonivelantes contribuiu para o espalhamento do material e reduziu o problema de segregação. O RCMG quando empregado em misturas de argamassas autonivelantes permite diminuir os impactos ambientais pertinentes das atividades de exploração e beneficiamento de rochas ornamentais.
\end{abstract}

Palavras-chave: Argamassa autonivelante. Resíduos do corte de mármores e granitos. Fíler calcário. Fibras de polipropileno. Propriedades mecânicas.

${ }^{1}$ Gabriela Azambuja Mendes ${ }^{1}$ Universidade do Estado de Santa Catarina Joinville - SC - Brasil

${ }^{2}$ Carmeane Effting ${ }^{2}$ Universidade do Estado de Santa Catarina Joinville - SC - Brasil

${ }^{3}$ Adilson Schackow ${ }^{3}$ Universidade do Estado de Santa Catarina Joinville - SC - Brasil

Recebido em 27/08/19 Aceito em 16/03/20

\begin{abstract}
Self-levelling mortars for subfloors were produced with marble and granite cutting waste (40\% and 50\% MGCW addition to the cement mass), and without the residue, varying the amounts of viscosity modifying additive and superplasticiser, water/cement ratio and cement/sand ratio. Dosages were tested with limestone filler instead of $M G C W$, with the addition of polypropylene fibres, and a commerciallyavailable product was studied. Properties in the fresh state (initial flow, healing time, flow retention after 20 and 30 min. and setting time), and hardened (specific mass, water absorption, void content, compressive strength and flexural traction strength) were tested according to ASTM 1708. The optimised mixture with 50\% MGCW, 0.55 water/cement factor, 1 : 1.5 cement/sand ratio (by mass using CPV-ARI cement) achieved a compressive strength of $38.89 \pm 2.10$ MPa at 28 days, presenting the best performance among the mortars tested. The addition of fine material in the self-levelling mortar dosages contributed to the spreading of the material and mitigated the segregation problem. When used in self-levelling mortarmixtures, MGCWreducesthe environmental impact of the exploration and processing of ornamental rocks.
\end{abstract}

Keywords: Self-levelling mortar. Marble and granite cutting waste. Limestone filer. Polypropylene fibres. Mechanical properties.

MENDES, G. A.; EFFTING, C.; SCHACKOW, A. Argamassa autonivelante com adição de resíduos de mármores e granitos: 403 propriedades físicas e mecânicas. Ambiente Construído, Porto Alegre, v. 20, n. 3, p. 403-418, jul./set. 2020. ISSN 1678-8621 Associação Nacional de Tecnologia do Ambiente Construído. 


\section{Introdução}

Devido à necessidade de racionalizar recursos naturais e atender a demanda de soluções construtivas rápidas estão sendo desenvolvidas argamassas autonivelantes para contrapiso. O material pode ser bombeado, e por se autonivelar pela ação do peso próprio e da gravidade é capaz de reduzir o número de trabalhadores envolvidos no processo construtivo, acelerando a execução dessa etapa em canteiro de obras se comparado com o sistema tradicional.

A camada de contrapiso é um estrato com as funções de regularizar o substrato, proporcionando uma superfície uniforme de apoio, coesa, aderida ou não, e adequada à camada de acabamento, podendo servir como camada de embutimento, caimento ou declividade. A Figura 1 exemplifica o sistema de piso proposto pela norma NBR 15575-3 (ABNT, 2013).

Argamassas autonivelantes são formulações de cimento Portland de alta resistência inicial (25\% a $45 \%$ da massa total) e areia fina quartzosa $(40 \%$ a $60 \%)$. Os $10 \%$ a $15 \%$ restantes da massa são formados por aditivos químicos e adições minerais destinados a modificar as características reológicas no estado fresco e as propriedades físico-mecânicas no estado endurecido, de modo a atender aos requisitos de instalação, carga, solicitação e durabilidade (NAKAKURA; BUCHER, 1997).

Vantagens no processo executivo das argamassas autonivelantes: ganhos de produtividade de mão de obra e no planejamento físico da obra; solução econômica e facilidade de uso; baixa retração; durabilidade; compatibilidade com a maioria das argamassas colantes do mercado (ALTOÉ et al., 2015).

De acordo com Freitas et al. (2010), argamassas autonivelantes possuem a propriedade de adensamento em virtude da reologia que as tornam bastante fluidas, sem que aconteça exsudação e segregação. Estudos estão sendo desenvolvidos com a busca por adições minerais que beneficiem as argamassas de forma sustentável.

O setor de exploração de rochas ornamentais no Brasil movimentou cerca de US\$ 5,0 bilhões em 2017 (ASSOCIAÇÃO..., 2018). As atividades relacionadas à extração e ao beneficiamento de rochas promovem um grande crescimento econômico no país, porém acarretam graves consequências ambientais nos resíduos sólidos gerados, sendo sua reciclagem e uso na construção civil (em compósitos de base cimentícia) uma boa alternativa na mitigação do impacto ambiental e na otimização de soluções visando ao desenvolvimento sustentável do setor (RAMOS et al., 2013).

Reis e Tristão (2007) descrevem o RCMG como extremamente fino, o material age como um fíler preenchendo os vazios na argamassa, contribuindo para melhoria de densidade e aceleração de hidratação do cimento Portland. Conforme Gonçalves, Moura e Molin (2002), a adição do resíduo resulta em incremento na coesão e consistência e, consequentemente, diminuição da exsudação, em função do efeito das partículas de pequeno diâmetro difundidas pela mistura, as quais atuam como uma barreira física para o movimento ascendente da água.

Neste estudo foram elaboradas misturas de argamassas autonivelantes de contrapiso com adição de RCMG sob os parâmetros descritos na norma americana C 1708 (AMERICAN..., 2016), visto que não existe norma brasileira que regulamente esse material. Após desenvolvimento da melhor dosagem, misturas adicionais foram testadas com fíler calcário em substituição ao RCMG para investigar a redução de segregação. Outras misturas com adição de fibras de polipropileno para investigar a resistência à tração na flexão foram analisadas, além de uma argamassa autonivelante disponível comercialmente. Dessa forma, foi possível comparar os resultados obtidos através dos ensaios nos estados fresco e endurecido, e validar as dosagens formuladas. Argamassa autonivelante ainda é um tema pouco estudado, e até desconhecido em algumas regiões. Este estudo contribui para o desenvolvimento do setor de tecnologia de argamassas e para a sustentabilidade, pois utiliza resíduos, que são recursos em potencial, e apresenta um desenvolvimento de dosagem que aprimora o processo construtivo.

\section{Programa experimental}

\section{Materiais utilizados}

Foram preparadas misturas de argamassas com diferentes proporções de cimento Portland CPII Z-32, areia natural, RCMG, água, aditivos superplastificante e modificador de viscosidade, com finalidade de encontrar dosagens de argamassas com a capacidade de se autonivelar. Misturas adicionais foram realizadas com cimento de alta resistência inicial CPV ARI-RS e com fíler calcário, para fins de comparação das propriedades nos estados fresco e endurecido.

404 Mendes, G. A.; Effting, C.; Schackow, A. 
Figura 1 - Exemplo de um sistema de piso e seus elementos

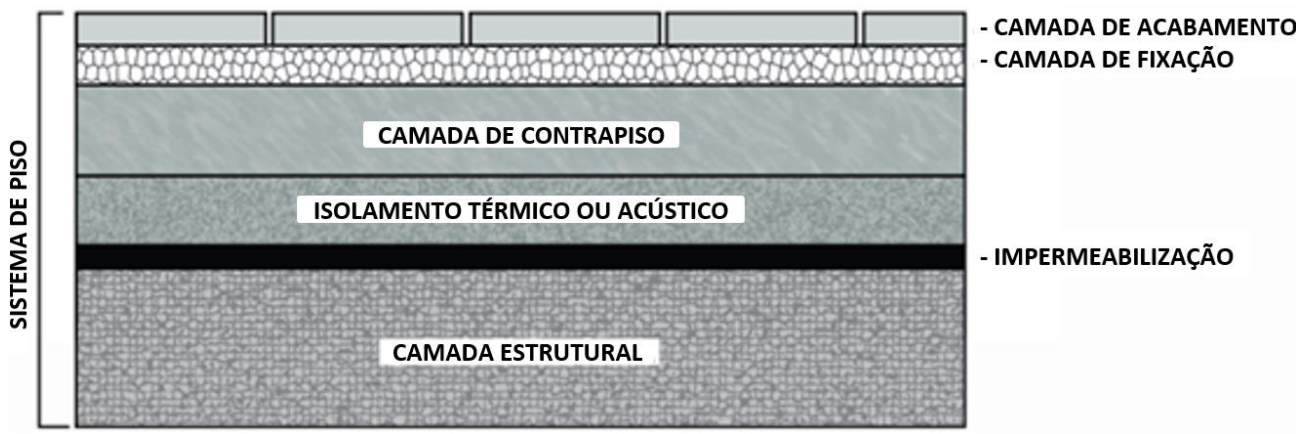

Fonte: NBR 15575-3 (ABNT, 2013).

O cimento Portland CPII Z-32é um cimento composto no qual a principal adição mineral é a pozolana e suas propriedades atendem desde estruturas de concreto até argamassas de revestimento e assentamento. Esse tipo de cimento apresenta tamanho de partículas menor que $41 \mu \mathrm{m}$ e possui em sua composição de $6 \%$ a $15 \%$ de pozolana, foi escolhido por ser largamente utilizado na região de norte de Santa Catarina e por apresentar diversas possibilidades de aplicação em argamassas e concretos.

Para comparação, foram realizados ensaios com o cimento de alta resistência inicial. $\mathrm{O}$ uso desse tipo de cimento nas dosagens de argamassas autonivelantes para contrapiso supre a necessidade de se utilizar e trabalhar sobre o pavimento, horas após a sua execução, característica de obras com alta velocidade de execução. O cimento CPV ARI-RS apresenta alta resistência e é indicado para situações em que se necessita de desforma rápida e alguma resistência a agentes abrasivos do meio ambiente, especialmente o ataque por sulfatos. Pode ser aplicado em artefatos, pré-moldados, blocos, pavers, concreto protendido de alto desempenho, pisos intertravados e pré-fabricados em geral.

O agregado miúdo utilizado nas argamassas possui dimensão máxima dos grãos de 1,18 mm e módulo de finura de 1,24, classificado como fino segundo a NBR NM 248 (ABNT, 2003). Esse tamanho de partícula corrobora com estudos elaborados por Canbaz, Topçu e Atesin (2016), cujo uso de areias naturais com granulometria de $0 \mathrm{~mm}$ a $1 \mathrm{~mm}$, se comparados com granulometria de $0 \mathrm{~mm}$ a $3 \mathrm{~mm}$, apresenta melhores resultados em argamassas autonivelantes, em relação ao adensamento, à resistência à compressão, à propagação de pulso e à absorção de água e capilaridade. A areia apresenta massa específica de $2,57 \mathrm{~g} / \mathrm{cm}^{3}$, segundo a NBR NM 52 (ABNT, 2009), e massa unitária aparente de 1,46 g/cm³, NBR NM 45 (ABNT, 2006).

O RCMG foi seco em estufa por 48 horas em temperatura aproximada de $100 \pm 2{ }^{\circ} \mathrm{C}$ e peneirado para eliminação de impurezas e para desaglomerar os grãos utilizando a peneira $150 \mu \mathrm{m}$. A massa específica do RCMG foi de $2,81 \mathrm{~g} / \mathrm{cm}^{3}$, obtida por picnometria com gás hélio. A granulometria do resíduo foi obtida a laser e apresentou tamanho médio dos grãos de 45,98 $\mu \mathrm{m}$ (D50\%) e diâmetro máximo dos grãos de 153,81 $\mu \mathrm{m}$ (D90\%). Conforme a Figura 2, o resíduo apresenta constância na distribuição granulométrica. O RCMG, em forma de pó, apresenta morfologia heterogênea de formato angular, com partículas maiores distribuídas entre as menores, conforme análise microestrutural, indicada na Figura 3. O ensaio de análise química por FRX (Tabela 1) apresenta os resultados para o RCMG e que foram comparados com demais autores.

Os resíduos ricos em óxidos fundentes $\left(\mathrm{Fe}_{2} \mathrm{O}_{3}+\mathrm{CaO}+\mathrm{K}_{2} \mathrm{O}\right)$ são originados dos processos de levigação, polimento ou granalha. Os óxidos de cálcio $(\mathrm{CaO})$ e de ferro $\left(\mathrm{Fe}_{2} \mathrm{O}_{3}\right)$ são oriundos da cal utilizada como lubrificante e da granalha como agente abrasivo no processo de beneficiamento das rochas ornamentais (SANTOS; DESTEFANI; HOLANDA, 2013).

A predominância do quartzo sílica $\left(\mathrm{SiO}_{2}\right)$ e, secundariamente, do feldspato alumina $\left(\mathrm{Al}_{2} \mathrm{O}_{3}\right)$ evidencia um resíduo sílico-aluminoso. Em menores teores há presença de minerais do grupo das micas $\left(\mathrm{Na}_{2} \mathrm{O}\right.$ e $\left.\mathrm{K}_{2} \mathrm{O}\right)$, compostos estes presentes em rochas graníticas (SATO; GALINA; TEIXEIRA, 2018). A presença do óxido de magnésio $(\mathrm{MgO})$ possivelmente é proveniente do desgaste das sapatas de polimento que são fabricadas com cimento sorel, formado por óxidos de magnésio e cloro tipicamente adotados na confecção das coroas abrasivas (AZEREDO et al., 2008). 
Figura 2 - Distribuição granulométrica do RCMG

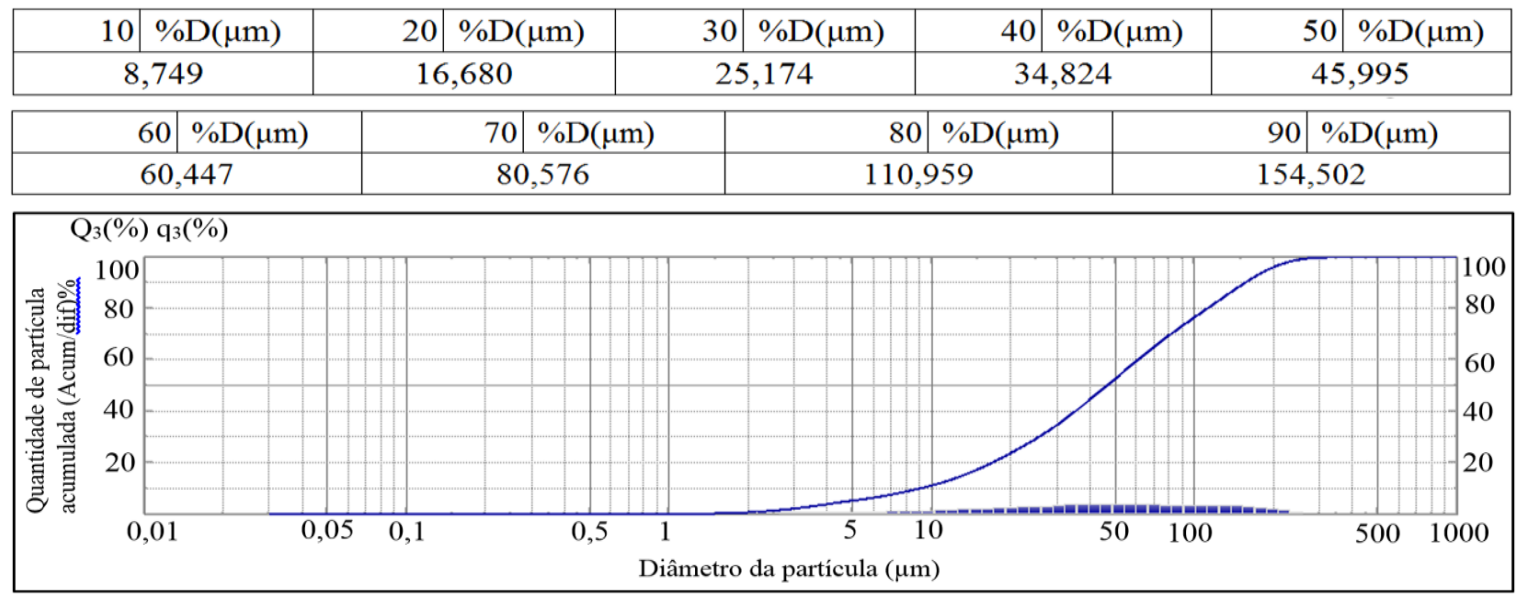

Figura 3 - Morfologia dos grãos do RCMG com aumento de 1.000x (a) e 950x (b)
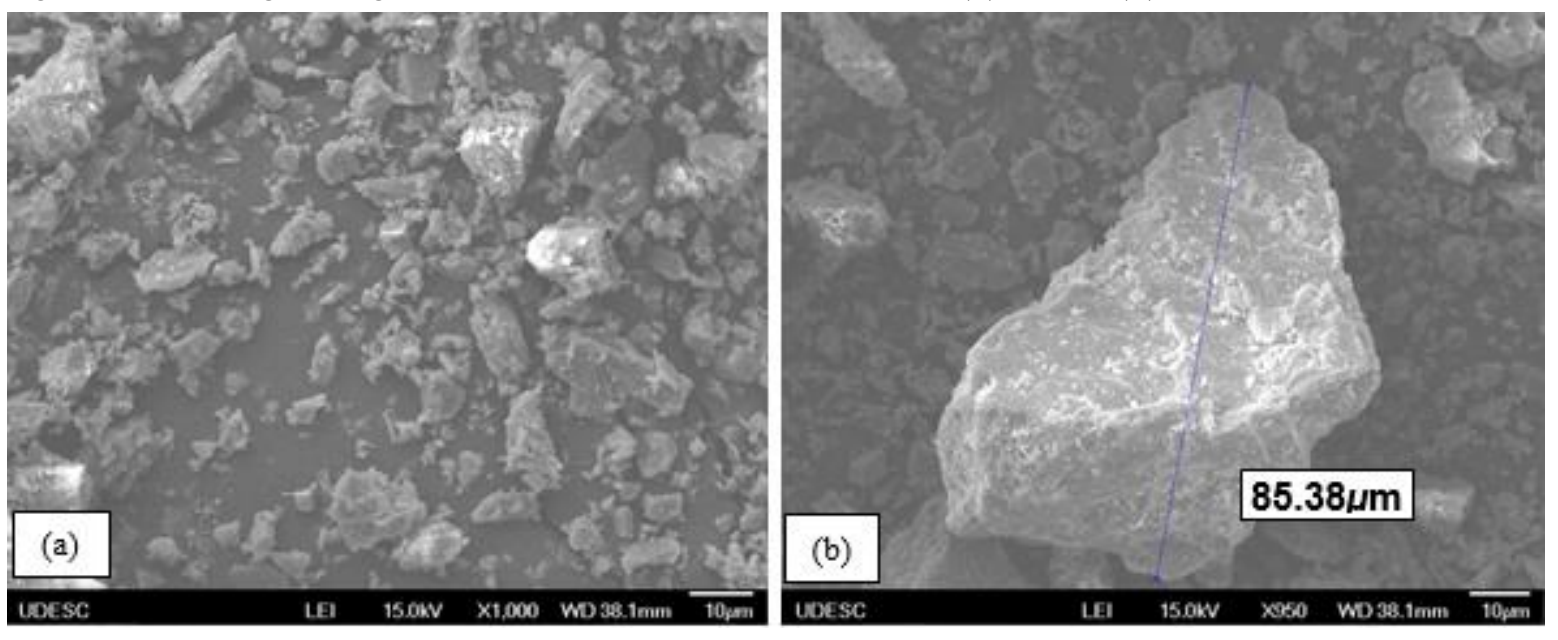

Tabela 1 - Análise química por FRX do RCMG

\begin{tabular}{c|c|c|c|c|c|c}
\hline $\begin{array}{c}\text { Teor de } \\
\text { óxido } \\
(\%)\end{array}$ & $\begin{array}{c}\text { Moura, } \\
\text { Gonçalves e } \\
\text { Leite (2002) }\end{array}$ & $\begin{array}{c}\text { Gonçalves, } \\
\text { Moura e Molin } \\
(\mathbf{2 0 0 2})\end{array}$ & $\begin{array}{c}\text { Mittri } \text { et } \\
\text { al. } \\
(\mathbf{2 0 1 8})\end{array}$ & $\begin{array}{c}\text { Silva, Severo } \\
\text { e Bezerra } \\
(\mathbf{2 0 1 5})\end{array}$ & $\begin{array}{c}\text { Matta } \text { et } \\
\text { al. } \\
(\mathbf{2 0 1 3})\end{array}$ & A autora \\
\hline $\mathrm{SiO}_{2}$ & 41,70 & 59,62 & 66,82 & 49,39 & 37,60 & 45,37 \\
$\mathrm{Fe}_{2} \mathrm{O}_{3}$ & 4,30 & 9,49 & 3,79 & 12,47 & 4,89 & 12,14 \\
$\mathrm{Al}_{2} \mathrm{O}_{3}$ & 8,5 & 12,77 & 13,50 & 18,52 & 9,04 & 17,14 \\
$\mathrm{CaO}$ & 21,00 & 4,83 & 3,44 & 6,33 & 17,70 & 14,78 \\
$\mathrm{MgO}$ & 2,00 & 1,96 & 0,93 & 4,11 & 8,21 & - \\
$\mathrm{N}_{2} \mathrm{O}$ & - & - & - & - & - & - \\
$\mathrm{K}_{2} \mathrm{O}$ & 2,30 & 5,30 & 3,83 & 3,40 & 2,5 & 5,12 \\
$\mathrm{Na}_{2} \mathrm{O}$ & 2,70 & 2,72 & - & 2,60 & 1,79 & - \\
$\mathrm{TiO}_{2}$ & 0,29 & - & 0,16 & 1,96 & 0,78 & 2,68 \\
$\mathrm{Outros}$ & 0,41 & 3,31 & 7,53 & 1,22 & 0,20 & 2,77 \\
\hline
\end{tabular}

O índice de desempenho do resíduo quanto à atividade pozolânica aos 28 dias de cura foi determinado através da resistência à compressão das seguintes argamassas: argamassa "A", contendo apenas cimento e areia proveniente do IPT, e argamassa "B", contendo 25\% de substituição em massa de cimento por RCMG, conforme norma NBR 5257 (ABNT, 2014). A argamassa "A" apresentou resistência à compressão aos 28 dias de 36,25 \pm 2,56 MPa e a argamassa "B" apresentou resistência igual a 23,79 4,84 MPa.

406 Mendes, G. A.; Effting, C.; Schackow, A. 
A partir dos resultados obtidos, o índice de desempenho com cimento Portland aos 28 dias para o RCMG foi de 65,6\%. A NBR 12653 (ABNT, 2014) estabelece que o índice mínimo para atividade pozolânica seja de 90,0\%. Assim, conclui-se que apesar do resíduo apresentar composição química que indica uma possível atividade pozolânica, o requisito mínimo de $90,0 \%$ não foi atendido, classificando o material como não pozolânico.

O RCMG, no seu estado natural, pode ser considerado uma adição mineral de preenchimento (fíler) dos poros intergranulares, por não possuir atividade química e ter uma alta superfície específica (SATO; GALINA; TEIXEIRA, 2018).

O fíler calcário foi utilizado para comparação dos resultados dos ensaios nos estados fresco e endurecido com os valores obtidos para as argamassas com RCMG, tendo em vista o uso do material por Carvalho (2015), Yang, Zhang e Yan (2016) e Araújo et al. (2015) como adição mineral em dosagens de argamassas autonivelantes. O material, quanto à granulometria, possui tamanho médio dos grãos de 37,38 $\mu \mathrm{m}$ (D50\%), diâmetro máximo dos grãos de 146,07 $\mu \mathrm{m}$ (D90\%), e 63,54\% passante na peneira $74 \mu \mathrm{m}$, caracterizando-se como material pulverulento. O diâmetro médio dos grãos é 18,70\% menor do que o RCMG. A Figura 4 apresenta a distribuição granulométrica do fíler calcário e a Figura 5 a morfologia dos grãos.

$\mathrm{O}$ aditivo químico superplastificante para dispersão dos grãos foi utilizado no estado líquido, de coloração marrom, sintético, baseado na cadeia de polímeros policarboxilatos. Segundo o laudo técnico, a amostra apresentou densidade de 1,10 g/ml, teor de sólidos de 45,6 \% e PH de 4,6. Para eliminar problemas de segregação dos agregados, foi utilizado aditivo químico modificador de viscosidade líquida, de coloração transparente. A amostra apresentou densidade de $1,00 \mathrm{~g} / \mathrm{ml}$, teor de sólidos de 0,680\% e PH de 6,9. Ambos os aditivos são indicados para todos os tipos de cimento.

Figura 4 - Distribuição granulométrica do fíler calcário

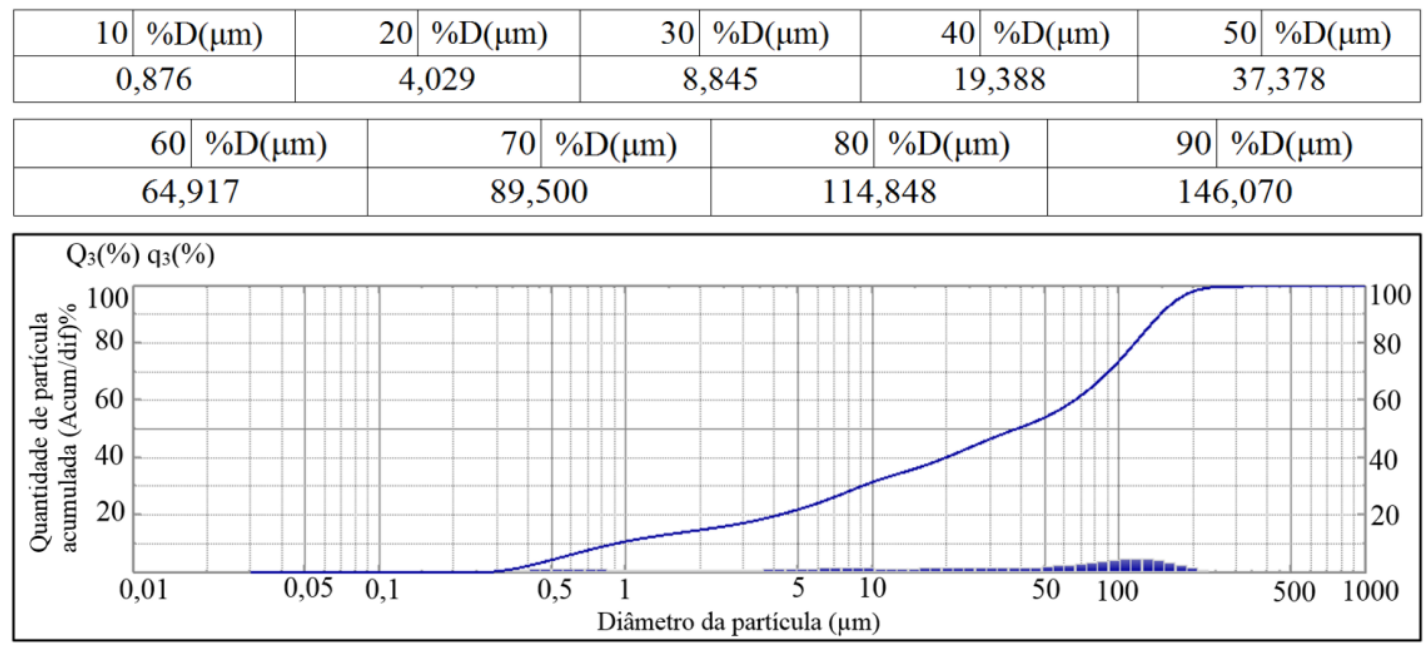

Figura 5 - Morfologia dos grãos de fíler calcário com aumento de 200x (a) e 1.500x (b)
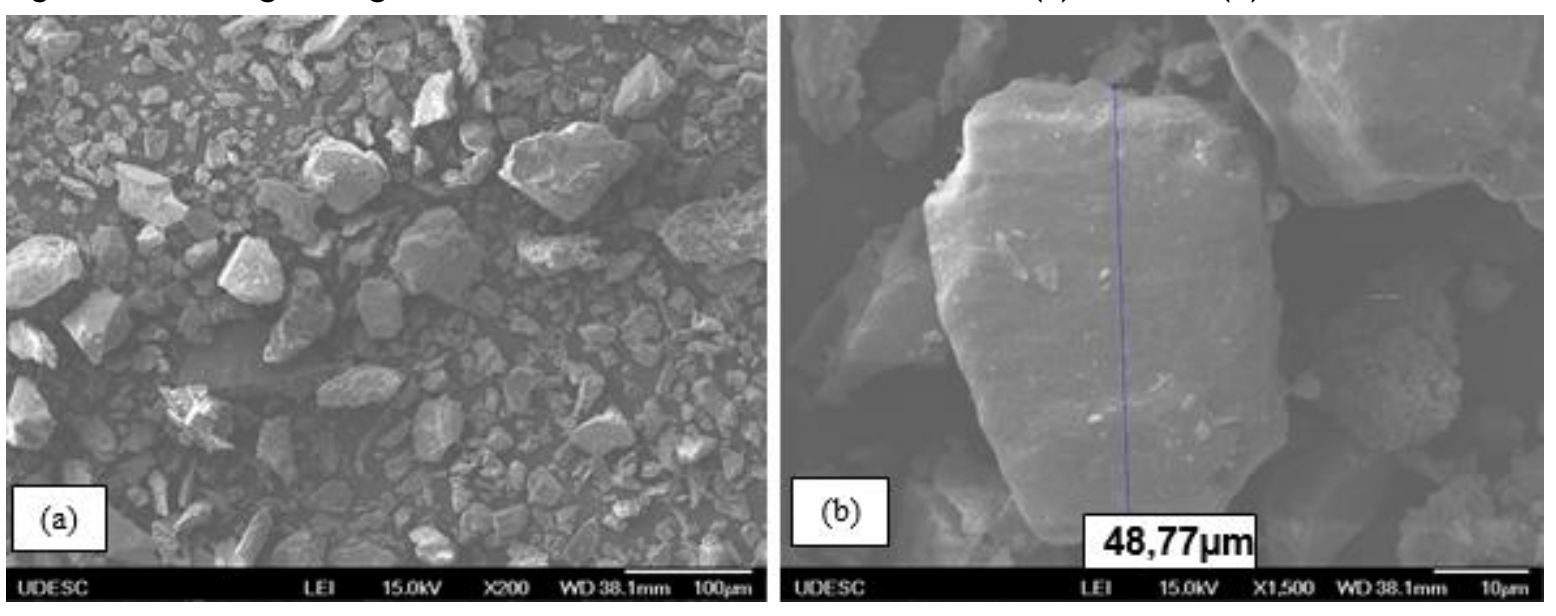
Para os ensaios de resistência à tração na flexão, foram confeccionados corpos de prova com fibras sintéticas de polipropileno na proporção de $4 \mathrm{~g}$ de fibras para $1 \mathrm{~kg}$ de cimento. As fibras são filamentos de polipropileno extremamente finos obtidos através do processo de extrusão (Figura 6). Após receberem tratamentos superficiais que facilitam a dispersão no concreto/argamassas, os filamentos são cortados dando origem às microfibras de polipropileno. As fibras possuem $6 \mathrm{~mm}$ de comprimento e $12 \mu \mathrm{m}$ de diâmetro, a área superficial é de $366 \mathrm{~m}^{2} / \mathrm{kg}$ e a densidade relativa de $0,91 \mathrm{~g} / \mathrm{cm}^{3}$. A fibra forma $25 \%$ de seu comprimento na ruptura por tração, possui ponto de fusão de $160{ }^{\circ} \mathrm{C}$ e ponto de ignição de $365^{\circ} \mathrm{C}$.

\section{Métodos experimentais}

Os materiais: areia, cimento, resíduo RCMG ou fíler calcário, água e aditivos foram adicionados ao misturador mecânico padronizados, com capacidade de $5 \mathrm{dm}^{3}$, conforme NBR 7215 (ABNT, 2019). Os ensaios de espalhamento inicial e retenção de fluxo foram realizados com um cilindro de $30 \mathrm{~mm} \times 50 \mathrm{~mm}$, chamado de anel de escoamento - flowring sobre uma base quadrada de vidro com as dimensões de $400 \mathrm{~mm}$ x $400 \mathrm{~mm}$ x 6 mm (Figura 7).

Logo após a mistura, a argamassa é inserida no cilindro, em um período de 2 segundos o anel é levantado a uma altura de $50 \mathrm{~mm}$ a $100 \mathrm{~mm}$ acima da base e o cronômetro iniciado. A argamassa deve ser espalhada durante $240 \pm 10 \mathrm{~s}$, para, a seguir, o diâmetro de espalhamento ser medido em duas direções, o diâmetro médio corresponde ao espalhamento inicial.

A argamassa é denominada autonivelante, de acordo com a norma C 1708 (AMERICAN..., 2016), se o diâmetro mínimo (Dmín) de espalhamento for de $125 \mathrm{~mm}$. Para a determinação da retenção de fluxo, o ensaio de espalhamento é repetido aos 20 e 30 minutos após a água ser adicionada à mistura da argamassa seca, então os diâmetros obtidos são comparados para avaliação da retenção de fluxo.

Figura 6 - Fibras de polipropileno com aumento de 50x

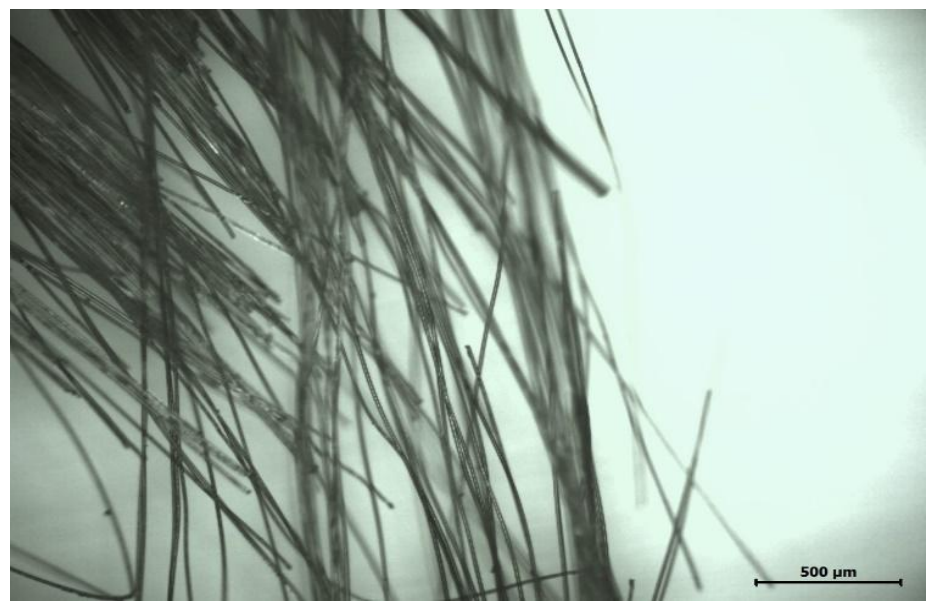

Figura 7 - Componentes para formulação da argamassa (a); ensaio de espalhamento (b)

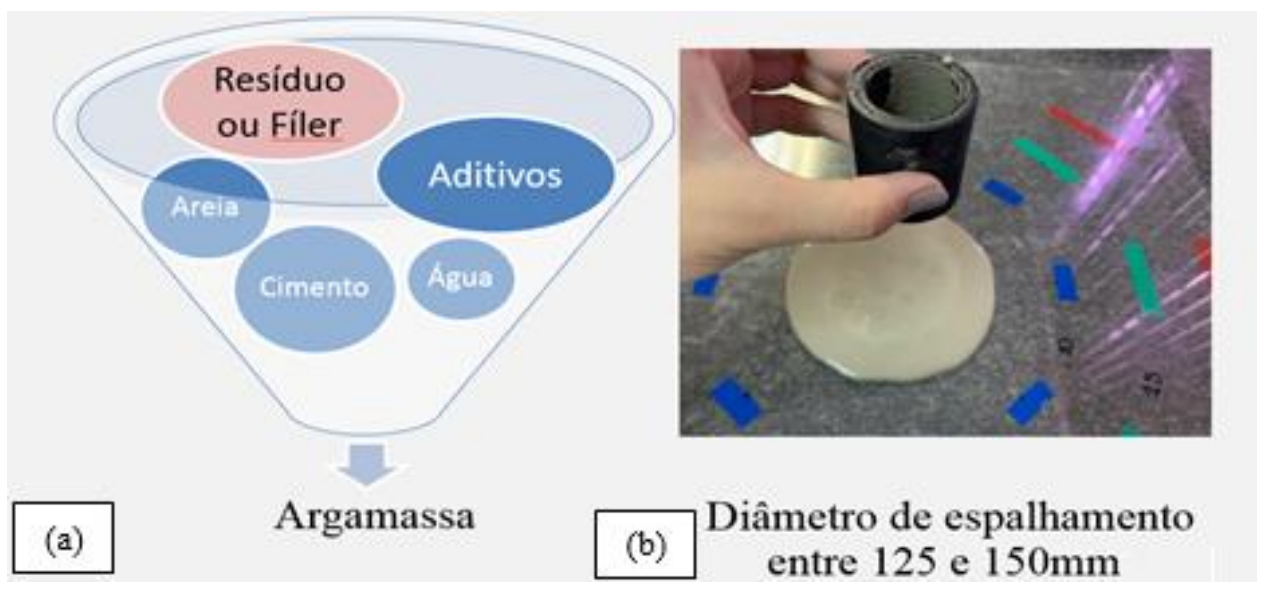

408 Mendes, G. A.; Effting, C.; Schackow, A. 
O procedimento para determinação do tempo de regeneração (Figura 8) consiste em realizar cortes na argamassa até que ela não retorne ao seu estado original, sem marcas, reentrâncias e desníveis na superfície. Logo após a mistura, a argamassa é depositada em uma fôrma retangular metálica com dimensões de 210 $\mathrm{mm} \times 210 \mathrm{~mm} \times 9 \mathrm{~mm}$. Os cortes iniciam após 10 minutos da mistura dos componentes da argamassa, os demais cortes são realizados com a periodicidade de 5 em 5 minutos, conforme a norma $\mathrm{C} 1708$ (AMERICAN..., 2016).

A determinação do tempo de início e fim de pega das argamassas autonivelantes foi realizada de acordo com norma americana C 191 (AMERICAN..., 2019), utilizando o Aparato de Vicat. Foram realizados ensaios periódicos de penetração com a agulha de Vicat de $1.0 \mathrm{~mm}$, registrando o tempo transcorrido entre o contato inicial da argamassa com a água e o tempo em que a penetração da agulha na amostra corresponde a $25 \mathrm{~mm}$, as medições iniciam 30 minutos após a mistura da argamassa. O tempo final de pega é determinado quando a agulha visivelmente não penetra na pasta.

Os ensaios para determinação da absorção de água, índice de vazios e massa específica das argamassas no estado endurecido foram realizados através de dois corpos de prova prismáticos com dimensões de $40 \mathrm{~mm} \mathrm{x}$ $40 \mathrm{~mm}$ x $160 \mathrm{~mm}$ para cada mistura ensaiada. Os procedimentos seguiram os parâmetros da NBR 9778 (ABNT, 2005).

Para os ensaios de resistência à compressão foram preparados nove corpos de prova cilíndricos com $50 \mathrm{~mm}$ de diâmetro e $100 \mathrm{~mm}$ de altura, ensaiados com 1, 7 e 28 dias de idade, três corpos de prova em cada data, respectivamente, para cada tipo de argamassa. Para resistência à flexão foram moldados seis corpos de prova prismáticos de $40 \mathrm{~mm}$ x $40 \mathrm{~mm}$ x $160 \mathrm{~mm}$ com 3 e 28 dias de idade, três corpos de prova em cada data, respectivamente, para cada tipo de argamassa, conforme a norma C 1708 (AMERICAN..., 2016). A prensa hidráulica disponível para os ensaios não registrou com precisão os resultados de resistência à tração na flexão com 1 dia de idade, conforme proposto pela norma C 1708 (AMERICAN..., 2016). Sendo assim, foi adotado como referência a primeira verificação de resistência aos 3 dias de idade.

Para a determinação da resistência à compressão e à tração na flexão das argamassas foi utilizado o equipamento EMIC PC200; a carga aplicada em cada amostra foi de $(500 \pm 50) \mathrm{N} / \mathrm{s}$ até ocorrer a ruptura dos corpos de prova.

\section{Resultados e discussões \\ Desenvolvimento das dosagens de argamassas}

Foram desenvolvidas misturas variando as proporções dos materiais em relação à massa de cimento, paralelamente foi ensaiada uma argamassa comercial, ensacada, na proporção em massa de $1: 0,2$ (materiais secos : água). Para validação das argamassas foram analisados os parâmetros de resistência à segregação e Dmín de $125 \mathrm{~mm}$ (Tabela 2). O cimento utilizado nas dosagens relacionadas foi o CPII Z-32. Na argamassa T11 ARI, excepcionalmente, foi utilizado o cimento CPV ARI-RS.

Figura 8 - Ensaio de healing time: argamassa no estado fresco (a); argamassa no estado endurecido (b)

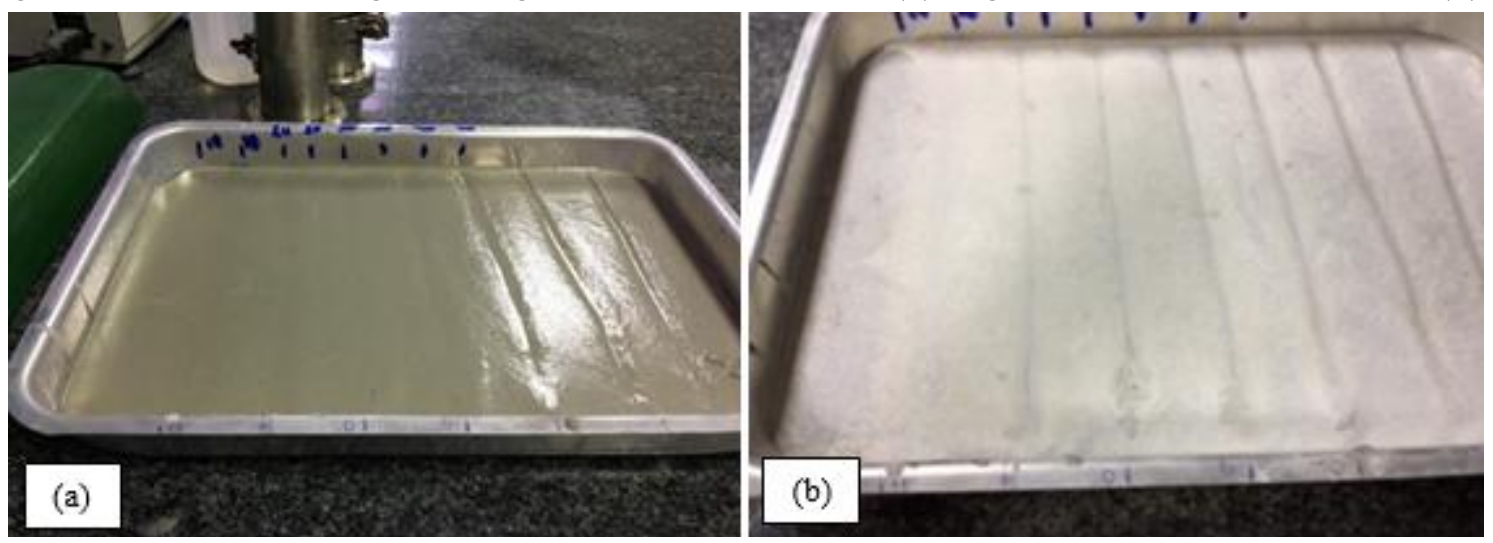


Tabela 2 - Dosagem de argamassas elaboradas

\begin{tabular}{|c|c|c|c|c|c|c|c|c|c|c|}
\hline \multirow{2}{*}{$\begin{array}{c}\text { Dosagem } \\
\mathbf{T}\end{array}$} & \multicolumn{8}{|c|}{ Proporção dos materiais } & \multirow{2}{*}{$\begin{array}{l}\text { Presença de } \\
\text { segregação }\end{array}$} & \multirow{2}{*}{$\begin{array}{l}\text { Dmín } \\
(\mathrm{mm})\end{array}$} \\
\hline & $\mathbf{C}$ & $\mathbf{A}$ & $\mathbf{R}$ & $\mathbf{F}$ & W/C & SP & V & $\mathbf{F i}$ & & \\
\hline $\mathrm{T} 1$ & 1 & 3,0 & - & - & 0,70 & $3,00 \%$ & $0,50 \%$ & - & Sim & $\geq 125$ \\
\hline $\mathrm{T} 2$ & 1 & 2,0 & - & - & 0,50 & $1,00 \%$ & $1,00 \%$ & - & Sim & $\geq 125$ \\
\hline $\mathrm{T} 3$ & 1 & 1,5 & - & - & 0,50 & $1,00 \%$ & $1,00 \%$ & - & Sim & $\geq 125$ \\
\hline $\mathrm{T} 4$ & 1 & 1,0 & - & - & 0,50 & $0,40 \%$ & $1,00 \%$ & - & Sim & $\geq 125$ \\
\hline T5 & 1 & 1,5 & - & - & 0,40 & $0,40 \%$ & $1,00 \%$ & - & Sim & $\geq 125$ \\
\hline T6 & 1 & 1,5 & - & - & 0,30 & $0,40 \%$ & $1,00 \%$ & - & Não & 115 \\
\hline $\mathrm{T} 7$ & 1 & 1,5 & - & - & 0,30 & $0,80 \%$ & $1,00 \%$ & - & Sim & $\geq 125$ \\
\hline T8 & 1 & 1,5 & - & - & 0,37 & $0,50 \%$ & $1,00 \%$ & - & Sim & 122 \\
\hline T9 & 1 & 1,5 & 0,5 & - & 0,45 & $0,50 \%$ & $1,00 \%$ & - & Não & 110 \\
\hline $\mathrm{T} 10$ & 1 & 1,0 & - & - & 0,33 & $0,33 \%$ & $0,67 \%$ & - & Não & 125 \\
\hline T11 RCMG (50\%) & 1 & 1,5 & 0,5 & - & 0,55 & $0,50 \%$ & $1,00 \%$ & - & Não & 133 \\
\hline T11 ARI (50\%) & 1 & 1,5 & 0,5 & - & 0,55 & $0,50 \%$ & $1,00 \%$ & - & Não & 135 \\
\hline T11 FIBRAS (50\%) & 1 & 1,5 & 0,5 & - & 0,55 & $0,50 \%$ & $1,00 \%$ & 0,004 & Não & 135 \\
\hline T11 FÍLER (50\%) & 1 & 1,5 & - & 0,5 & 0,55 & $0,50 \%$ & $1,00 \%$ & - & Não & 136 \\
\hline T12 RCMG (40\%) & 1 & 1,5 & 0,4 & - & 0,50 & $0,50 \%$ & $1,00 \%$ & - & Não & 140 \\
\hline $\mathrm{T}_{\text {COMERCIAL }}$ & \multicolumn{8}{|c|}{$\begin{array}{l}\text { Formulado na proporção 1:0,2 (materiais secos:água); } \\
3.400 \mathrm{~g} \text { de argamassa para } 690 \mathrm{~g} \text { de água } \\
\end{array}$} & Não & 135 \\
\hline \multicolumn{11}{|c|}{$\begin{array}{l}\text { Nota: Legenda: } \\
\text { Dmín: (quando submetido ao ensaio de espalhamento); } \\
\text { C - Cimento; A - Areia; R - Resíduo; } \\
\text { F - Fíler; } \\
\text { W - Água (Water); } \\
\text { SP - Superplastificante; } \\
\text { V - Modificador de viscosidade; e } \\
\text { Fi - Fibras. }\end{array}$} \\
\hline
\end{tabular}

Para se obter a mistura T10, a argamassa sem resíduo foi otimizada. Primeiramente, a dosagem inicial foi de 1:1,5 (relação entre cimento e areia) conforme os traços anteriores T3, T5, T6, T7, T8 e T9, sem adicionar resíduos e alterando o fator água-cimento. As argamassas elaboradas com a proporção de 1:1,5, variando o teor de aditivo superplastificante e o fator água-cimento, não apresentaram propriedades autonivelantes. Posteriormente, então, foi aumentado o teor de cimento na mistura (material fino) que, na proporção de $1: 1$ (cimento:areia), sem alterar aquantidade de aditivos em relação à dosagem T9, melhorou o problema de segregação. A proporção final dos materiais da argamassa T10 foi de 1:1:0,33:0,0033:0,067 (C:A:W:SP:V). Dessa forma, constatou-se que a adição de finos, superplastificante, modificador de viscosidade é fundamental para o espalhamento da argamassa, de forma coesa e homogênea, eliminando o problema de segregação. Canbaz, Topçu e Atesin (2016) recomendam até 1\% de superplastificante.

A propriedade autonivelante está associada à ação dispersante do aditivo superplastificante aliada à presença de finos na dosagem. A dosagem T10 foi elaborada contendo cimento e areia, a proporção dos materiais foi de 1:1. Para diminuir a quantidade de cimento foi necessário introduzir material de granulometria similar, nesse caso o RCMG ou fíler calcário.

A Tabela 3 apresenta um resumo das principais características das misturas estudadas. As dosagens elaboradas com o RCMG obtiveram bons resultados quanto ao Dmínde espalhamento e à resistência à segregação.

O RCMG, quando introduzido na argamassa, em substituição ao cimento Portland, proporcionou as características desejadas para autonivelamento. A diminuição da quantidade de cimento e a utilização de resíduo contribuíram para um desenvolvimento sustentável do setor.

Na dosagem T11 FÍLER o RCMG foi substituído por fíler calcário para comparação dos resultados nos estados fresco e endurecido. Na mistura T11 FIBRAS foram acrescentadas fibras de polipropileno na dosagem. As argamassas T11 RCMG (50\%), T11 FÍLER (50\%), T12 RCMG (40\%) e T ensaio de espalhamento, podem ser visualizadas na Figura 9. 
Tabela 3 - Resumo das principais características das misturas estudadas

\begin{tabular}{|c|c|}
\hline Proporção dos materiais & $\begin{array}{l}\text { Imagens do ensaio de } \\
\text { espalhamento }\end{array}$ \\
\hline $\begin{array}{c}\mathrm{T} 3 \\
\mathrm{C}: \mathrm{A}: \mathrm{W}: \mathrm{SP}: \mathrm{V} \\
1: 1,5: 0,5: 0,001: 0,01\end{array}$ & \\
\hline \multicolumn{2}{|l|}{$\begin{array}{l}\text { Nesta dosagem a quantidade de areia, água e de aditivo SP foi } \\
\text { reduzida, porém ainda ocorreu segregação da argamassa. }\end{array}$} \\
\hline $\begin{array}{c}\mathrm{T} 5 \\
\mathrm{C}: \mathrm{A}: \mathrm{W}: \mathrm{SP}: \mathrm{V} \\
1: 1,5: 0,4: 0,004: 0,01\end{array}$ & \\
\hline \multicolumn{2}{|l|}{$\begin{array}{c}\text { A argamassa ficou mais coesa e apresentou menor segregação. } \\
\text { Para diminuir o excesso de água, o fator W/C, na próxima } \\
\text { mistura T6, foi reduzido. }\end{array}$} \\
\hline $\begin{array}{c}\mathrm{T} 6 \\
\mathrm{C}: \mathrm{A}: \mathrm{W}: \mathrm{SP}: \mathrm{V} \\
1: 1,5: 0,3: 0,004: 0,01\end{array}$ & \\
\hline \multicolumn{2}{|l|}{$\begin{array}{l}\text { A argamassa ficou demasiadamente seca, e não houve fluidez } \\
\text { com o Dmínde } 125 \mathrm{~mm} .\end{array}$} \\
\hline \multirow{2}{*}{\multicolumn{2}{|c|}{$\begin{array}{l}\text { Nesta mistura a quantidade de aditivo superplastificante foi } \\
\text { aumentada significantemente e foi observada segregação na } \\
\text { argamassa. }\end{array}$}} \\
\hline & \\
\hline $\begin{array}{c}\text { T8 } \\
\text { C: A: W: SP: V } \\
1: 1,5: 0,37: 0,005: 0,01\end{array}$ & \\
\hline \multicolumn{2}{|l|}{$\begin{array}{l}\text { Nesta mistura a argamassa apresentou diâmetro de } \\
\text { espalhamento de } 122 \mathrm{~mm} \text { e foi observada segregação. }\end{array}$} \\
\hline \multirow{2}{*}{\multicolumn{2}{|c|}{$\begin{array}{l}\text { A argamassa não apresentou fluidez suficiente, o diâmetro de } \\
\text { espalhamento foi inferior a } 125 \mathrm{~mm} \text {. Não houve segregação. }\end{array}$}} \\
\hline & \\
\hline $\begin{array}{c}\mathrm{T} 10 \\
\mathrm{C}: \mathrm{A}: \mathrm{W}: \mathrm{SP}: \mathrm{V} \\
1: 1: 0,33: 0,0033: 0,067\end{array}$ & \\
\hline $\begin{array}{l}\text { Dosagem de argamassa autonivelante sem a presença de } \\
\text { resíduos e com características autonivelantes. }\end{array}$ & \\
\hline
\end{tabular}


Figura 9 - Ensaio de espalhamento: argamassas T11 RCMG (50\%) (a); T11 FíLER (50\%) (b); T12 RCMG (40\%) (c); TCOMERCIAL (d)
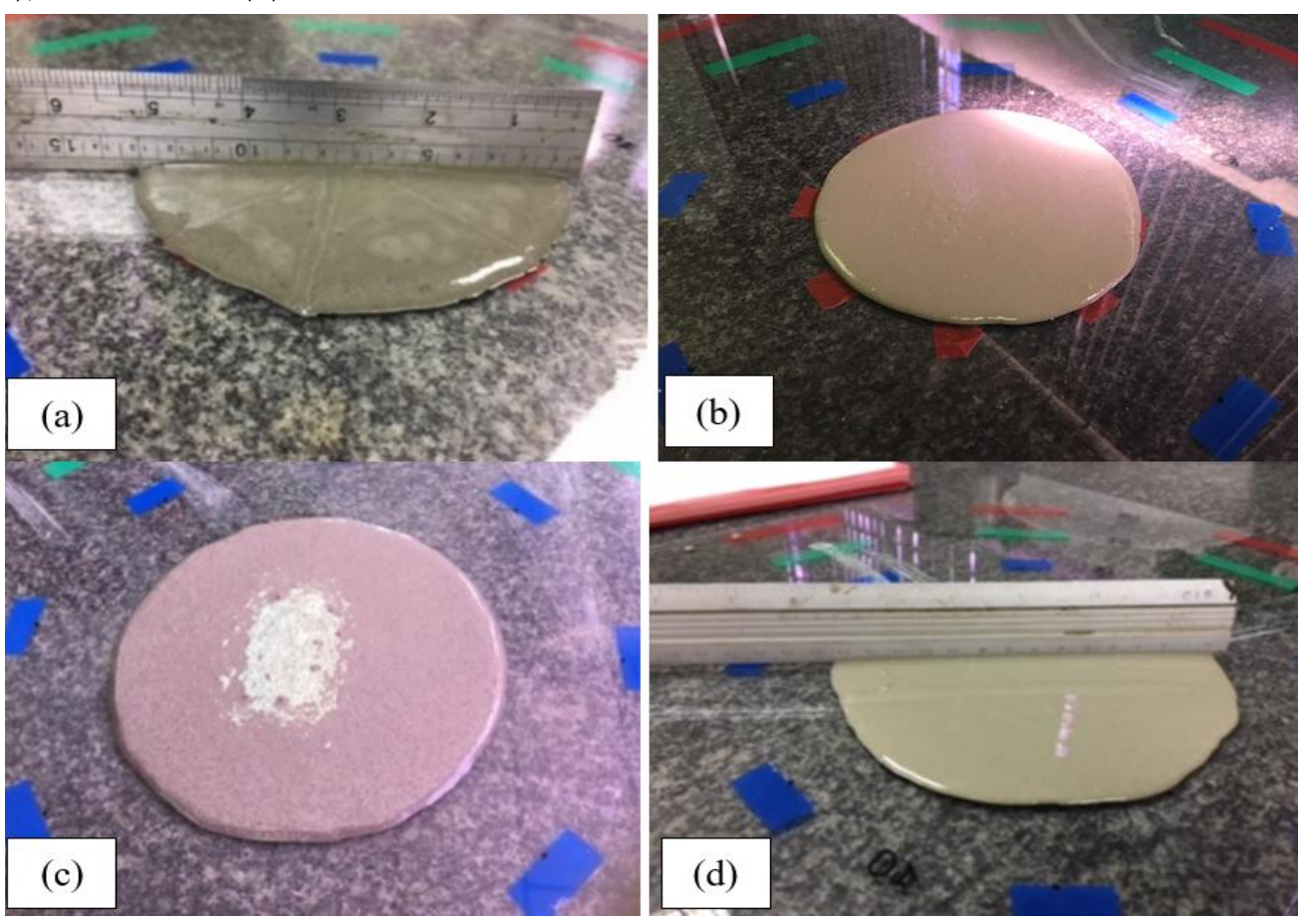

\section{Retenção de fluxo - flowretention e tempo de regeneração - healing time}

As argamassas T11 RCMG (50\%), T12 RCMG (40\%), T11 ARI (50\%), T11 FIBRAS (50\%) e T11 FILER (50\%) não apresentaram retenção de fluxo, o diâmetro de espalhamento inicial , e após 30 minutos se mantiveram iguais, conforme a Tabela 4. A argamassa comercial reduziu $20 \mathrm{~mm}$ após 20 minutos da mistura inicial e $40 \mathrm{~mm}$ após 30 minutos. O tempo de regeneração para todas as dosagens de argamassas foi entre 15 e 20 minutos.

\section{Tempo de pega setting time}

O ensaio de tempo de pega foi realizado para as dosagens T11 RCMG (50\%), T11 ARI (50\%), T12 RCMG

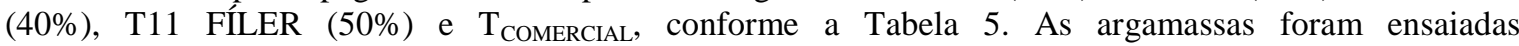
paralelamente, nas mesmas condições de umidade e temperatura.

O tempo de pega das argamassas formuladas foi pelo menos $3 \mathrm{x}$ maior do que a argamassa $\mathrm{T}_{\mathrm{COMERCIAL}}$ ensaiada.

A substituição do cimento CP II-Z32 utilizado na dosagem T11 RCMG (50\%) pelo cimento CPV-ARI-RS utilizado na argamassa T11 ARI não diminuiu os tempos de início e fim de pega.

A argamassa T12 RCMG (40\%) obteve um tempo de início de pega 47,86\% menor, comparado com a argamassa T11 RCMG (50\%), e tempo de fim de pega 48,46\% menor. Tal diferença está relacionada com o fator água/cimento da dosagem T12 RCMG (40\%), que é menor em relação às outras argamassas e pode estar relacionada com a menor quantidade de RCMG presente no traço.

A incorporação de fíler calcário (T11 FÍLER) em substituição ao RCMG (T11 RCMG (50\%)) diminuiu o tempo de início de pega em $44,12 \%$ e o fim de pega em $35,81 \%$.

\section{Massa específica, índice de vazios e absorção de água}

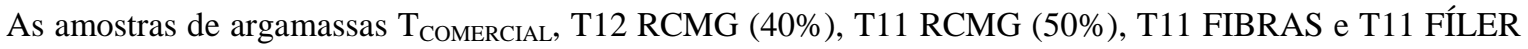
(50\%) foram ensaiadas para determinação de absorção de água, índice de vazios e massa específica. Os resultados encontram-se na Tabela 6 . 
Tabela 4 - Resultados dos ensaios de retenção de fluxo e tempo de regeneração

\begin{tabular}{l|c|c|c|c|c|c}
\hline \multicolumn{1}{c|}{ Argamassas } & T $_{\text {COMERCIAL }}$ & $\begin{array}{c}\text { T12 } \\
\text { RCMG } \\
(\mathbf{4 0 \% )}\end{array}$ & $\begin{array}{c}\text { T11 } \\
\text { RCMG } \\
(\mathbf{5 0 \%})\end{array}$ & $\begin{array}{c}\text { T11 } \\
\text { ARI } \\
\mathbf{( 5 0 \% )}\end{array}$ & $\begin{array}{c}\text { T11 } \\
\text { FIBRAS } \\
(\mathbf{5 0 \%})\end{array}$ & $\begin{array}{c}\text { T11 } \\
\text { FILER } \\
(\mathbf{5 0 \%})\end{array}$ \\
\hline $\begin{array}{l}\text { Espalhamento inicial } \\
(\mathrm{mm})\end{array}$ & 135 & 140 & 133 & 135 & 135 & 136 \\
\hline $\begin{array}{l}\text { Espalhamento } \\
20 \text { min (mm) }\end{array}$ & 115 & 140 & 133 & 135 & 135 & 136 \\
\hline $\begin{array}{l}\text { Espalhamento } \\
30 \text { min (mm) }\end{array}$ & 95 & 140 & 133 & 135 & 135 & 136 \\
\hline $\begin{array}{l}\text { Tempo de regeneração } \\
\text { (min) }\end{array}$ & $15-20$ & $15-20$ & $15-20$ & $15-20$ & $15-20$ & $15-20$ \\
\hline
\end{tabular}

Tabela 5 - Tempo de pega para as argamassas testadas

\begin{tabular}{l|c|c|c}
\hline \multicolumn{1}{c|}{ Argamassas } & $\begin{array}{c}\text { Tempo de início de } \\
\text { pega (h:min) }\end{array}$ & $\begin{array}{c}\text { Tempo de fim de } \\
\text { pega (h:min) }\end{array}$ & $\begin{array}{c}\text { Diferença } \\
\text { (h:min) }\end{array}$ \\
\hline T11 RCMG (50\%) & $11: 20$ & $12: 20$ & $01: 00$ \\
T11 ARI (50\%) & $11: 33$ & $12: 23$ & $00: 50$ \\
T12 RCMG (40\%) & $05: 54$ & $06: 26$ & $00: 32$ \\
T11 FILER (50\%) & $06: 20$ & $07: 55$ & $01: 35$ \\
T $_{\text {COMERCIAL }}$ & $01: 40$ & $02: 06$ & $00: 26$ \\
\hline
\end{tabular}

Tabela 6 - Valores de absorção de água, índice de vazios e massa específica para as argamassas

\begin{tabular}{l|c|c|c}
\hline \multicolumn{1}{c|}{ Argamassas } & Absorção de água (\%) & Índice de vazios (\%) & Massa específica $\left(\mathbf{g} / \mathbf{c m}^{3}\right)$ \\
\hline $\mathrm{T}_{\text {COMERCIAL }}$ & $12,31 \pm 0,11$ & $26,31 \pm 0,27$ & $2,54 \pm 0,01$ \\
$\mathrm{~T} 12$ RCMG (40\%) & $9,70 \pm 0,23$ & $21,65 \pm 0,52$ & $2,57 \pm 0,01$ \\
T11 RCMG (50\%) & $9,87 \pm 0,27$ & $22,05 \pm 0,39$ & $2,58 \pm 0,02$ \\
T11 FIBRAS (50\%) & $11,96 \pm 0,00$ & $26,23 \pm 0,00$ & $2,62 \pm 0,00$ \\
T11 FÍLER (50\%) & $9,99 \pm 0,41$ & $22,20 \pm 1,02$ & $2,67 \pm 0,03$ \\
\hline
\end{tabular}

As dosagens T12 RCMG (40\%), T11 RCMG (50\%) e T11 FILER (50\%) apresentaram valores similares de absorção de água e índice de vazios, variando 0,29\% para absorção de água e 0,55\% para índice de vazios.

$\mathrm{A}$ argamassa $\mathrm{T}_{\text {COMERCIAL }}$ foi a dosagem que apresentou maior absorção de água e índice de vazios entre todas as argamassas testadas, absorveu $23,22 \%$ a mais de água em comparação ao traço T11 FÍLER (50\%) e consequentemente apresentou $18,51 \%$ maior quantidade de vazios.

A incorporação de fibras de polipropileno na dosagem T11 RCMG (50\%), resultando na mistura T11 FIBRAS (50\%), aumentou a absorção de água em $21,18 \%$ e a quantidade de vazios em $18,96 \%$.

A massa específica variou $0,13 \mathrm{~g} / \mathrm{cm}^{3}$ entre todas as dosagens formuladas, apresentando, dessa forma, grande similaridade entre os resultados obtidos.

\section{Resistência à compressão}

Os ensaios de resistência à compressão das argamassas foram realizados para as dosagens: $\mathrm{T}_{\mathrm{COMERCIAL}}$, T12 RCMG (40\%), T11 RCMG (50\%), T11 ARI e T11 FÍLER, conforme Figura 10.

Tendo em vista os resultados de resistência à compressão obtidos com as 5 dosagens, o traço T11 ARI (50\% de RCMG e CP V ARI-RS) apresentou valores superiores a 1, 7 e 28 dias, se comparados com as demais argamassas elaboradas.

Para fins de comparação e análise dos dados obtidos com as argamassas autonivelantes testadas, a norma C1708 (AMERICAN..., 2016) divulgou uma série de estudos interlaboratoriais. 
Figura 10 - Resultados de resistência à compressão das argamassas em 1, 7 e 28 dias

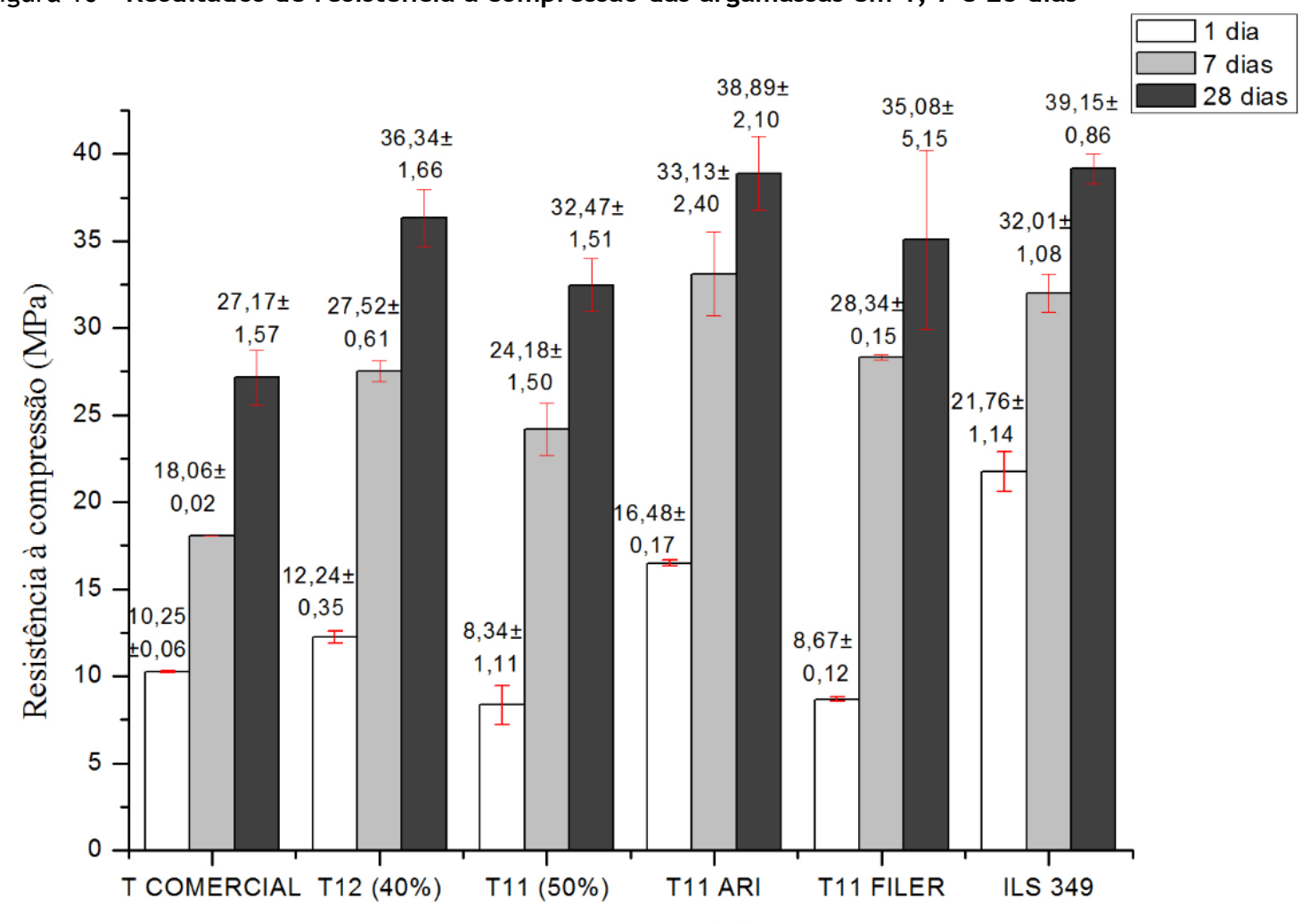

Argamassas estudadas

O estudo interlaboratorial "ILS n. 349" da norma C1708 (AMERICAN..., 2016) apresentou resultados de ensaios realizados com 7 dosagens de argamassas comerciais autonivelantes, com 5 réplicas, nas datas de 1, 7 e 28 dias. A resistência à compressão média registrada pela ILS n. 349 em 1 dia foi de 21,76 1,14 MPa, sendo esta 24,26\% maior que a resistência média obtida na mistura T11 ARI deste estudo. Aos 7 dias a resistência obtida no ILS foi de $32,01 \pm 1,08 \mathrm{MPa}, 3,5 \%$ menor que a mistura T11 ARI. Aos 28 dias a resistência média foi de 39,15 $\pm 0,86 \mathrm{MPa}, 0,66 \%$ superior à mesma mistura.

Para os 7 dias, considerando as amostras independentes e paramétricas, com um intervalo de confiança de 95\%, utilizando o teste t de Student, a amostra T11 ARI não se mostra diferente dos resultados obtidos na ILS (p-valor $=0,5040$ ). Para os 28 dias, aplicando o mesmo teste, as amostras também foram consideradas iguais $(\mathrm{p}$-valor $=0,8497)$.

A dosagem T12 RCMG (40\%) apresentou melhores resultados de resistência à compressão em 1, 7 e 28 dias se comparados com a argamassa T11 RCMG (50\%). O aumento da quantidade de RCMG e do fator água/cimento diminui em $31,86 \%$ a resistência com 1 dia, $12,14 \%$ aos 7 dias e $10,65 \%$ aos 28 dias. O RCMG é caracterizado como inerte, sem atividade pozolânica, reduzindo os valores de resistência à compressão quando adicionado de $40 \%$ para $50 \%$ da massa de cimento nas dosagens de argamassas.

A argamassa $\mathrm{T}_{\text {COMERCiAL }}$ apresentou os menores valores de resistência à compressão com 7 e 28 dias, em relação às demais argamassas estudadas. No entanto, com 1 dia o ganho de resistência foi 22,9\% maior do que a dosagem T11 RCMG (50\%) e 18,22\% superior à T11 FÍLER.

A substituição de RCMG por fíler calcário(T11 FÍLER) aumentou a resistência à compressão em todas as idades analisadas, em comparação com a dosagem T11 RCMG (50\%), a qual possui adição de RCMG nas mesmas proporções, em 1 dia aumentou 3,96\%, em 7 dias 17,20\% e em 28 dias 8,04\%.

Li et al. (2018), em seus estudos com argamassas autonivelantes, encontraram valores de resistência à compressão entre $21,3 \pm 0,8 \mathrm{MPa}$ e $39,3 \pm 0,8 \mathrm{MPa}$ aos 56 dias, variando o tipo de cura. Pereira e Camarini (2018), para uma dosagem de referência, com proporção de 1:2 (cimento:areia), encontraram 33,27 MPa de resistência aos 28 dias de idade.

414 Mendes, G. A.; Effting, C.; Schackow, A. 


\section{Resistência à tração na flexão}

Para os ensaios de resistência à tração das argamassas ensaiadas foram: $\mathrm{T}_{\text {COMERCIAL, T12 RCMG (40\%), T11 }}$ RCMG (50\%), T11 ARI, T11 FIBRAS e T11 FÍLER. Os resultados estão apresentados na Figura 11.

Para análise dos resultados as amostras foram consideradas pequenas, independentes e não paramétricas (observadas após teste de Shapiro-Wilk). As amostras foram comparadas entre si através do teste de Kruskal-Wallis e analisadas duas a duas através do teste de Dunn, para concluir se os parâmetros modificados entre as dosagens alteraram os valores de resistência.

Verifica-se através do teste de Kruskal-Wallis que os valores de resistência à tração aos 3 dias são considerados diferentes ( $\mathrm{p}$-valor = 0,0124), assim como aos 28 dias ( $\mathrm{p}$-valor = 0,0109) comparando todas as dosagens de argamassas com um nível de significância de $95 \%$.

Ao se analisar a influência das fibras na dosagem T11 RCMG (50\%), estatisticamente não é observada diferença nos valores de resistência à tração na flexão aos 3 dias (p-valor = 0,7593) e aos 28 dias (p-valor = 0,4906). A presença de fibras, nas proporções de 4 gramas de fibra para cada quilograma de cimento (dosagem T11 FIBRAS), não aumentou a resistência da argamassa nesse parâmetro. No entanto, ao observar a Figura 12, verifica-se que a argamassa, apesar de apresentar uma ruptura, mantém-se unida pelas fibras incorporadas, sem desprender-se.

A dosagem T12 RCMG (40\%) não apresentou vantagens quanto à resistência à tração aos 3 dias, com uma resistência média considerada estatisticamente igual à resistência da mistura T11 RCMG (50\%), (p-valor = 0,8482). No entanto, para os ensaios realizados aos 28 dias, a dosagem T12 RCMG (40\%) apresentou uma resistência 42,47\% superior à mistura T11 (50\%).

Comparando-se as argamassas T11 ARI e T11 RCMG (50\%), verifica-se que a substituição do cimento CP II-Z32 pelo cimento CP V-ARI-RS aumentou a resistência à tração em 30,35\% aos 3 dias e 40,71\% aos 28 dias, sendo eficiente no parâmetro analisado.

A substituição do RCMG por fíler calcário, resultando na mistura (T11 FÍLER), aumentou a resistência à tração em 65,17\% em 3 dias e 45,86\% em 28 dias, em comparação com a dosagem T11 RCMG (50\%), dessa forma conclui-se que o a adição de fíler calcário melhora a propriedade testada em ambas as idades ensaiadas.

Figura 11 - Resistência à tração na flexão das argamassas aos 3 e 28 dias

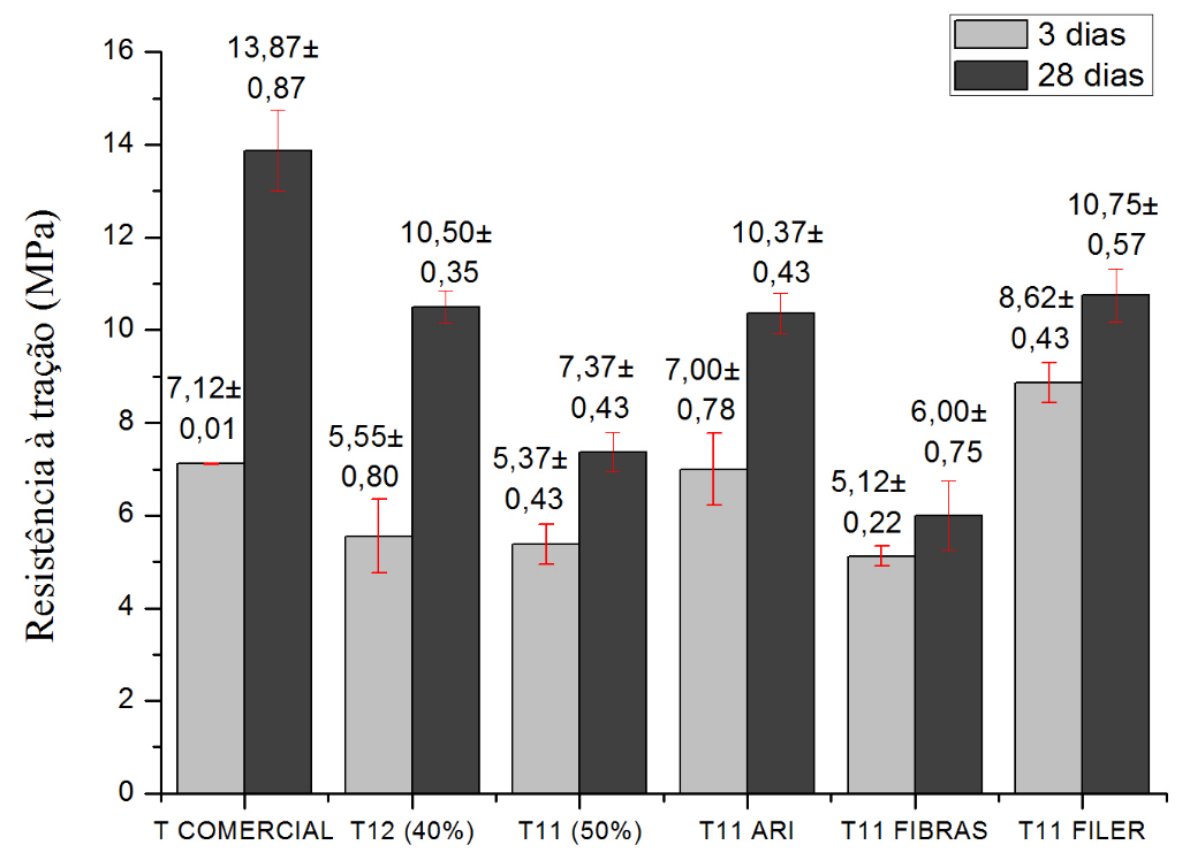

Argamassas estudadas 


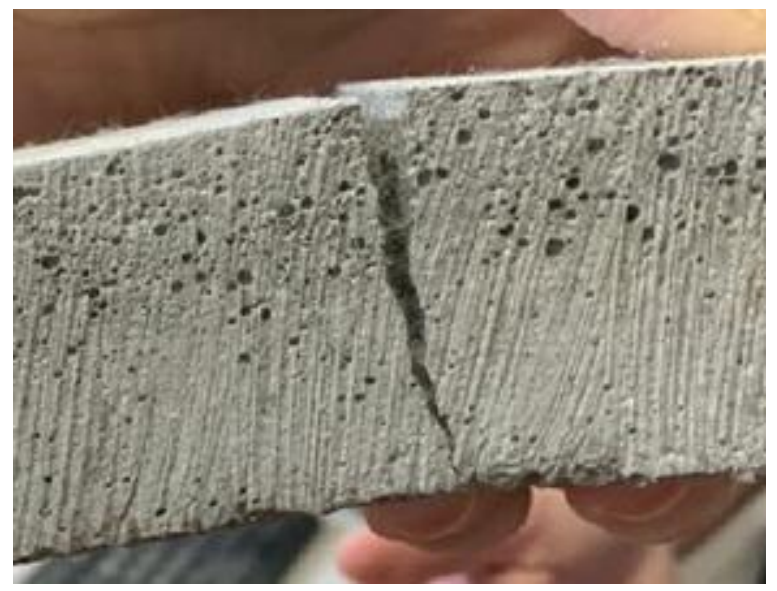

Mohammadhosseini, Awal e Yatim (2017) realizaram ensaios com teores de fibras de polipropileno com 20 $\mathrm{mm}$ de diâmetro, variando de $0 \%$ a $1,25 \%$, em volume, em dosagens de concreto. A resistência à tração aumentou com a adição de fibras, no entanto o comportamento foi semelhante para todos os teores de fibras de polipropileno testados. Para os ensaios de resistência à compressão, os autores identificaram uma redução da resistência com o aumento do teor de fibras.

A mistura $\mathrm{T}_{\text {COMERCIAL, }}$ aos 3 dias de idade, estatisticamente obteve uma resistência igual à mistura T11 ARI (p-valor $=0,877$ ), no entanto aos 28 dias foi $33,75 \%$ maior.

Li et al. (2018) encontraram valores de resistência à tração na flexão entre 6,0 $\pm 0,5 \mathrm{MPa}$ e 10,0 $\pm 0,6 \mathrm{MPa}$ aos 56 dias, variando o tipo de cura. Pereira e Camarini (2018), em sua dosagem de referência, encontraram 7,41 MPa de resistência aos 28 dias de idade.

\section{Conclusões}

O RCMG é extremamente fino, morfologicamente o material é heterogêneo, de formato angular e possui o diâmetro médio dos grãos de $45,98 \mu \mathrm{m}$. Em relação à análise química do RCMG, o material não possui atividade pozolânica e seus óxidos fundentes $\left(\mathrm{Fe}_{2} \mathrm{O}_{3}+\mathrm{CaO}+\mathrm{K}_{2} \mathrm{O}\right)$ têm provável origem pelos processos de levigação, polimento ou granalha.

Argamassas autonivelantes foram formuladas ajustando a dosagem de cimento, areia, agregado fino (RCMG ou fíler calcário) e aditivos (superplastificante e modificador de viscosidade) sem apresentar segregação e com diâmetro de espalhamento $\geq 125 \mathrm{~mm}$. A adição de finos, aditivos superplastificante e modificador de viscosidade é fundamental para o espalhamento das argamassas autonivelantes, de forma coesa e homogênea, eliminando o problema de segregação.

No estado fresco, as argamassas formuladas não apresentaram retenção de fluxo no período de 30 minutos, enquanto a argamassa comercial reduziu cerca de $30 \%$ da capacidade de espalhamento no mesmo período. Todas as dosagens elaboradas apresentaram tempo de pega superior a cinco horas, suficiente para realização do bombeamento do material, caso necessário.

A incorporação de fibras de polipropileno na dosagem T11 (50\%), resultando na mistura T11 FIBRAS, aumenta a quantidade de vazios no interior da argamassa em 18,96\% e consequentemente eleva a absorção de água em $21,17 \%$. Todas as argamassas formuladas apresentaram teor de vazios e absorção de água inferiores à dosagem comercial.

As dosagens elaboradas apresentaram resistência à compressão superior aos $30 \mathrm{MPa}$ aos 28 dias, corroborando com os resultados da ILS n. 349. O traço T11 ARI apresentou a maior resistência com 1, 7 e 28 dias, sendo sua resistência final 43,14\% maior quando comparada ao traço comercial.

A resistência à tração na flexão das argamassas formuladas foi $\geq 6,00 \mathrm{MPa}$ aos 28 dias de idade. A presença de fibras de polipropileno na proporção de 4 gramas de fibras para cada quilograma de cimento não influencia nos resultados de resistência à tração na flexão na dosagem T11 FIBRAS (50\%). 
As argamassas desenvolvidas nesta pesquisa apresentaram resultados coerentes com a norma, quando avaliadas as propriedades físicas nos estados fresco e endurecido. Em sua maioria os resultados obtidos com as adições de RCMG e de fíler calcário foram superiores quando comparados com a argamassa comercial testada, indicando a possibilidade de aplicação das dosagens na construção civil, como camada de contrapiso. As fibras contribuíram para a resistência à tração na flexão da argamassa. Consequentemente, conclui-se que o RCMG pode ter um destino sustentável quando empregado em dosagens de argamassas autonivelantes, reduzindo, dessa forma, os impactos ambientais pertinentes das atividades de exploração e beneficiamento de rochas ornamentais.

\section{Referências}

ALTOÉ, C. R. et al. Contrapiso autonivelante. In: SIMPÓSIO SUL CAPIXABA DE ENGENHARIA, São Camilo, 2015. Anais [...] São Camilo, 2015.

AMERICAN SOCIETY FOR TESTING AND MATERIALS. C191: standard test methods for time of setting of hydraulic cement by vicat needle. Pennsylvania, 2019.

AMERICAN SOCIETY FOR TESTING AND MATERIALS.C1708/C1708M: self-leveling mortars containing hydraulic cements. Pennsylvania, 2016.

ARAÚJO, T. R. de et al. Efeitos da incorporação do fíler calcário e do resíduo da biomassa da cana-deaçúcar em argamassas autonivelantes. In: SIMPÓSIO BRASILEIRO DE TECNOLOGIA DAS ARGAMASSAS, 11., Porto Alegre, 2015. Anais [...] Porto Alegre, 2015.

ASSOCIAÇÃO BRASILEIRA DA INDÚSTRIA DE ROCHAS ORNAMENTAIS. Perfil das atividades setoriais no Brasil. Distrito Federal, julho de2018. Informe anual.

ASSOCIAÇÃO BRASILEIRA DE NORMAS TÉCNICAS. NBR 7215: cimento Portland: determinação da resistência à compressão. Rio de Janeiro, 2019.

ASSOCIAÇÃO BRASILEIRA DE NORMAS TÉCNICAS. NBR 15575: edificações habitacionais: desempenho. Rio de Janeiro, 2013.

ASSOCIAÇÃO BRASILEIRA DE NORMAS TÉCNICAS. NBR 9778: argamassa e concreto endurecidos: determinação da absorção de água, índice de vazios e massa específica. Rio de Janeiro, 2005.

ASSOCIAÇÃO BRASILEIRA DE NORMAS TÉCNICAS. NBR 12653: materiais pozolânicos: requisitos. Rio de Janeiro, 2014.

ASSOCIAÇÃO BRASILEIRA DE NORMAS TÉCNICAS. NBR NM 248: agregados: determinação composição granulométrica. Rio de Janeiro, 2003.

ASSOCIAÇÃO BRASILEIRA DE NORMAS TÉCNICAS. NBR NM 45: agregados: determinação da massa unitária e do volume de vazios. Rio de Janeiro, 2006.

ASSOCIAÇÃO BRASILEIRA DE NORMAS TÉCNICAS. NBR NM 52: agregado miúdo: determinação da massa específica e massa específica aparente. Rio de Janeiro, 2009.

AZEREDO, S. R. de et al. Desenvolvimento de um novo compósito abrasivo de desbaste de rochas ornamentais. Matéria (rio de Janeiro), Rio de Janeiro, v. 13, n. 1, p. 203-208, mar. 2008.

CANBAZ, M.; TOPÇU, İ. B.; ATESIN, Ö. Effect of admixture ratio and aggregate type on self-leveling screed properties. Construction and Building Materials, v. 116, p. 321-325, jul. 2016.

CARVALHO, H. D. S. Análise da retração por secagem em argamassas autonivelantes utilizando adições minerais como substitutos parciais do cimento Portland. Florianópolis, 2015. 140 f. Dissertação (Mestrado em Engenharia Civil) - Escola de Engenharia, Universidade Federal de Santa Catarina, Florianópolis, 2015.

GONÇALVES, J. P.; MOURA, W. A.; DAL MOLIN, D. C. C. Avaliação da influência da utilização do resíduo de corte de granito (RCG), como adição, em propriedades mecânicas do concreto. Ambiente Construído, Porto Alegre, v. 2, n. 1, p. 53-68, jan./mar. 2002.

FREITAS, E. R. F. de et al. Estudo das adições e aditivos minerais nas propriedades de argamassas autonivelantes. In: CONGRESSO NORTE NORDESTE DE PESQUISA E INOVAÇÃO, 5., Maceió, 2010. Anais [...] Maceió, 2010. 
LI, N. et al. Experimental study of calcium sulfoaluminate cement-based self-leveling compound exposed to various temperatures and moisture conditions: Hydration mechanism and mortar properties. Cement and Concrete Research, v. 108, p. 103-115, jun. 2018.

MATTA, V. R. P. da et al. Efeitos da adição do Resíduo de Corte de Mármore e Granito (RCMG) no desempenho de argamassas de cimento Portland no estado endurecido. Periódico Eletrônico Fórum Ambiental da Alta Paulista, v. 9, n. 1, p. 87-104, nov. 2013.

MITTRI, S. H. M. et al. Assessment of the pozzolanic activity of ornamental stone waste after heat treatment and its effect on the mechanical properties of concretes. Revista Ibracon de Estruturas e Materiais, v. 11, n. 6, p. 1186-1207, dez. 2018.

MOHAMMADHOSSEINI, H.; AWAL, A. S. M. A.; YATIM, J. B. M. The impact resistance and mechanical properties of concrete reinforced with waste polypropylene carpet fibres. Construction and Building Materials, v. 143, p. 147-157, jul. 2017.

MOURA, W.; GONÇALVES, J. P..; LEITE, R. da S. utilização do resíduo do corte de mármore e granito em argamassa de revestimento e confecção de lajotas para piso. Sitientibus, Feira de Santana, v. 1, n. 26, p. 49-61, jan./jun. 2002

NAKAKURA, E. H.; BUCHER, H. R. E. pisos autonivelantes: propriedades e instalação. In: SIMPÓSIO BRASILEIRO DE TECNOLOGIA DAS ARGAMASSAS, 2., São Paulo, 1997. Anais [...] Salvador, 1997.

PEREIRA, V. M.; CAMARINI, G. Fresh and hardened properties of self-leveling mortars with porcelain and red ceramic wastes. Advances In Civil Engineering, p. 1-11, jun. 2018.

RAMOS, T. et al. Granitic quarry sludge waste in mortar: effect on strength and durability. Construction and Building Materials, v. 47, p. 1001-1009, out. 2013.

REIS, A. S. dos; TRISTÃO, F. A. Análise de argamassas com resíduo de corte de rochas ornamentais. In: CONGRESSO NACIONAL DE ARGAMASSAS DE CONSTRUÇÃO, 2., Lisboa, 2007. Anais

[...] Lisboa, 2007.

SANTOS, M. M. A.; DESTEFANI, A. Z.; HOLANDA, J. N. F. Caracterização de resíduos de rochas ornamentais provenientes de diferentes processos de corte e beneficiamento. Revista Matérias, Campo dos Goytacazes, v. 18, n. 4, p. 1442-1450, 16 abr. 2013.

SATO, V. Y.; GALINA, A. P. L.; TEIXEIRA, J. E. S. L. Contribution to the rheological study of cementitious pastes with addition of residues from the processing of ornamental rocks. Revista Ibracon de Estruturas e Materiais, v. 11, n. 6, p. 1284-1307, dez. 2018.

SILVA, L. T. M. de S.; SEVERO, C. G. S.; BEZERRA, U. A. Utilização do resíduo de granito como substituição parcial do cimento na produção de concreto. In: CONGRESSO TÉCNICO CIENTÍFICO DA ENGENHARIA E DA AGRONOMIA, 1., Fortaleza, 2015. Anais [...] Fortaleza, 2015.

YANG, L.; ZHANG, Y.; YAN, Y. Utilization of original phosphogypsum as raw material for the preparation of self-leveling mortar. Journal of Cleaner Production, v. 127, p. 204-213, jul. 2016.

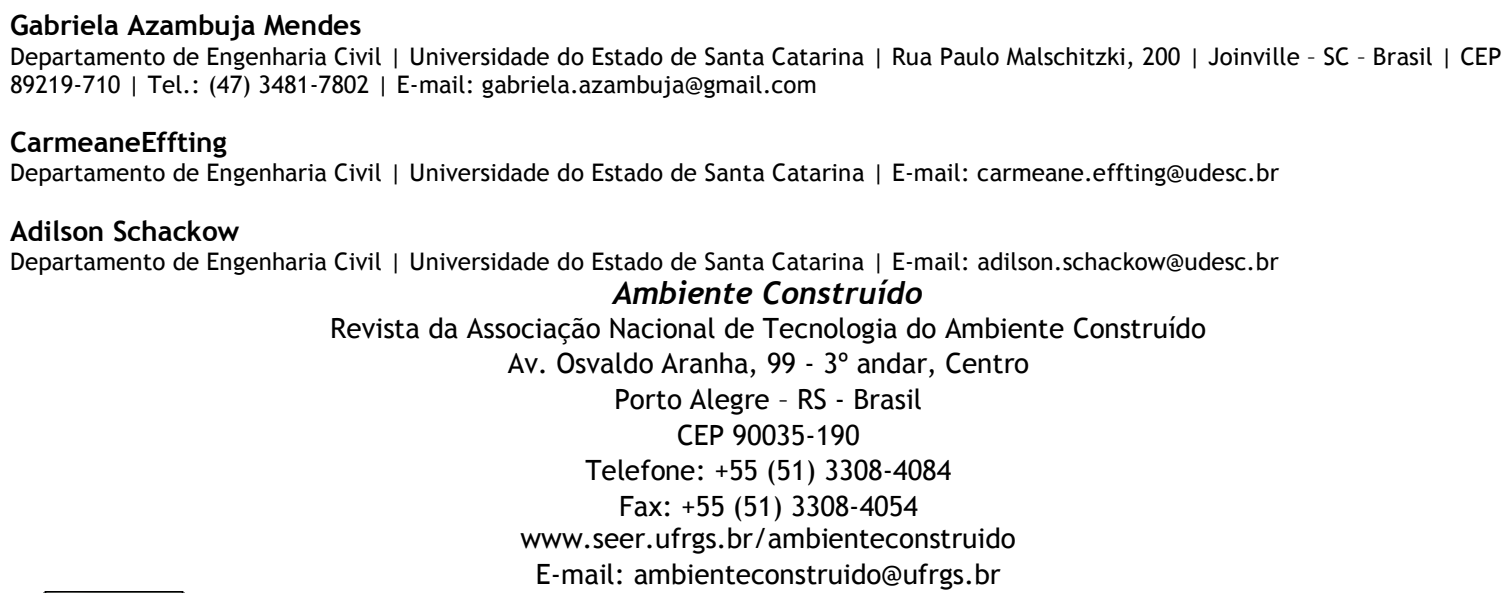

